\title{
CHARACTERIZATION OF POLYLACTIDE (PLA) COMPOSITE REINFORCED WITH BIOWASTE
}

\author{
C.C, Odili' ${ }^{1}$, O.P, Gbenebor ${ }^{2}$, O.E, Adesola ${ }^{3}$, S.O, Adeosun ${ }^{4}$
}

1 Department of Metallurgical and Materials Engineering, University of Lagos, Nigeria. E-Mail: chiosa.odili@gmail.com

2 Department of Metallurgical and Materials Engineering, University of Lagos, Nigeria. E-Mail: ogbenebor@unilag.edu.ng

3 Department of Metallurgical and Materials Engineering, University of Lagos, Nigeria. E-Mail: segun.adesola@gmail.com

4 Department of Metallurgical and Materials Engineering, University of Lagos, Nigeria. E-Mail: sadeosun@unilag.edu.ng

HTTP://DX.DOI.ORG/10.30572/2018/KJE/120208

\section{ABSTRACT}

The suitability of watermelon (WM) and Albizia lebbeck benth (ALB) seed particles as reinforcement for polylactide (PLA) were investigated. The composites were produced using $150 \mu \mathrm{m}$ particle size reinforcement additions from 5 to $15 \mathrm{wt} . \%$. The microstructure, tensile properties and crystallinity were evaluated. The results showed $5 \mathrm{wt}$.\% filler gave a better tensile strength of $1.70 \mathrm{MPa}$ and $1.86 \mathrm{MPa}$ for watermelon, and ALB reinforced composites respectively, over unreinforced PLA (1.11MPa). This is attributed to strong interfacial bond between polymer and the bio-waste fillers, as observed from the SEM micrographs. The crystallite size of neat PLA, 5wt.\%WM and 5wt.\% ALB are 4.9, 0.2, and 1.9 A respectively. The sorption ability of polymer is inversely proportional to the degree of crystallinity. Thus, the smaller the crystal size, the better the crystalline index, with improved hydrophilicity and tensile strength properties. These bio-composites can be used in the abdominal part of human skin (1-24 MPa).

\section{KEYWORDS}

Watermelon seed, Albizia lebbeck seeds, Composites, Polylactide (PLA) Polymer, Tensile strength 


\section{INTRODUCTION}

To achieve sustainable development and green economy, a brand-new material devoid of environmental pollution and dependence on fossil fuel is highly essential (Li et al., 2017). In recent times a large number of materials used in every day applications are polymer, owing to lightness in weight, ease of manufacturing and low cost (Antonio et al., 2018). One of such versatile polymers is polylactide (PLA) - a biopolymer derived from renewable and degradable material such as sugar cane, corn and rice. The degradation product of $\mathrm{PLA}$ like $\mathrm{CO}_{2}$ and $\mathrm{H}_{2} \mathrm{O}$ are neither toxic nor carcinogenic to the human body, thus making it an excellent material for tissue engineering, packaging and biomedical applications (e.g., sutures, drug delivery system). PLA has excellent mechanical property as well as being biodegradable and biocompatible. However, its low degradation rate and brittleness ( $<10 \%$ elongation), limit its area of application. To improve the properties of PLA reinforcements like natural fibres, chitin, chitosan and starch have been used. Natural fibres used are bast fibres (flax, jute, hemp, kenaf, and ramie), leaf fibres (agave, abaca, and pineapple), fruit and seed fibres (coir, cotton, and kapok), core fibres (kenaf, hemp, and jute), grass and reed fibres (bamboo, elephant grass, wheat, corn, and rice) and are wood (Ramengmawii et al., 2018). Natural fibre is a renewable resource and because of environmental concern of fossil-based polymers the incorporation of these into polymer is on high demand, as a biomaterial for reinforcing polymer (Sanjay et al., 2016). Antonio et al. (2018) studied the effect of mixture ratio on the mechanical properties of PLA reinforced with mixed cellulose and chitin nano fibre. The results showed that micro fibrillated cellulose (MFC) blended with chitin nanofiber (ChNF) in the ratio of 1:1 at $50 \mathrm{wt} \%$ reinforcement gave the best tensile strength over neat PLA and the individual reinforcement. This was attributed to the presence of hydroxyl group in chitin and cellulose. Chen et al. (2015) reinforce PLA with halloysite nanotube (HNT), and observed that there was an increase in stiffness and modulus with the highest tensile strength of $62.7 \mathrm{MPa}$ at $5 \mathrm{wt} \% \mathrm{HNT}$. Jia et al. (2013) noticed that the tensile strength of both PLA and PLA-PBS (polybutylene succinate) composites increased by $10-40 \%$ while the initial modulus is $2-6$ times higher than that measured for PLA and PBS films.

Kamarudin et al. (2018) studied the mechanical and morphological properties of PLA bio composites prepared with epoxidized jatropha oil (EJO) vegetable oil-based plasticiser and kenaf fibres. The addition of EJO with 40 wt.\% kenaf fibre loading on PLA improved the mechanical properties of the polymer composites. Sun et al. (2017) worked on PLA bio composites reinforced with short coir fibre $(1,3,5$, and $7 \mathrm{wt} \%)$. Short coir fibres were treated 
with blend of hydrogen peroxide and sodium hydroxide solutions to improve the adhesion between fibres and PLA matrix. The best impact strength results were obtained for $3 \mathrm{wt} \%$ PLA/treated coir fibre bio composites, where the impact strength was increased by $\sim 28 \%$ compared to the neat PLA. The tensile modulus of PLA bio composites increased with the treated coir fibre content. Gbenebor et al. (2020) reinforced low density polyethene (LDPE) with albizia lebbeck benth particles and obtained an 331\% improvement in tensile strength of virgin LDPE (0.36 MPa). The use of natural fibre/particle to reinforce polymer is not new. Water melon seed has some content that is known to promote fast healing of wound burns, acceleration of growth and restoration of a healthy skin (Mohammed, 2006). On the other hand, albizia lebbeck benth (ALB) is often used in medicine as it possesses antimicrobial and antioxidant properties (Shahid and Firdou, 2012). However, literature information is scarce on the use of watermelon and albizia lebbeck seeds particles to reinforce PLA for possible use in soft tissue repair. Thus, the aim of this work is to characterize watermelon and ALB seeds particles reinforced PLA for improve tensile strength of PLA for medical applications.

\section{METHODOLOGY}

\subsection{Raw Materials:}

The matrix PLA pellets were procured from Suzhou, China, while the watermelon and Albizia lebbeck seeds were obtained from University of Lagos environment. Watermelon fruit is a green oval in shape with a sweet taste, it is composed of flesh (68\%), seed (2\%) and rind 30\% of the total mass of the fruit; the chemical composition include crude protein, crude fibre, Vitamin A, fat and flavonoid. While the ALB seeds contains crude fibre, lipid ash carbohydrate. Watermelon and ALB seeds were sun- dried for 3 weeks at an average daily temperature of $32^{\circ} \mathrm{C}$ and thereafter oven dried at $120^{\circ} \mathrm{C}$ for another 3 weeks, to remove the moisture and water content of the seeds. Thereafter, the seeds were ground to $150 \mu \mathrm{m}$ particle

\subsection{Casting of the composite}

Various techniques have been used to fabricate PLA, such as injection moulding, extraction, blow moulding, fibre spinning and casting (Clarinval, 2002). However, in this work the wooden mould was used in casting the composite. The PLA was melted at $180^{\circ} \mathrm{C}$, and the weight fractions of the reinforcements were added to the molten PLA, stirred until a homogenous mixture was obtained before casting into the wooden mould and allowed to cool at $27^{\circ} \mathrm{C}$. 


\subsection{Mechanical test}

The tensile test of the composite produced was done using an Instron computerised double column universal tensile testing machine model 3369 located at the Energy Centre, Obafemi Awolowo University, Ile-Ife, Nigeria. It has a load capacity of $50 \mathrm{KN}$ and operates at a loading rate/strain rate of $5 \mathrm{~mm} / \mathrm{min}$.

\subsection{XRD analysis}

The X-ray diffractometry measurements were performed on an EMPYREAN XRD-6000 diffractometer using $\mathrm{Cu}$ Ka radiation $(\lambda=1.540598 \mathrm{~A} \circ$, Ni-filter) at $40 \mathrm{kV}, 30 \mathrm{~mA}$. The samples without preferred orientations were scanned in steps of 0.03 in the 2 Theta ranges from 4.99 to 75 using a count time of $29.7 \mathrm{~s}$ per step. Crystalline size normal to hkl plane $\mathrm{d}(\mathrm{hkl})$ was calculated from the full width at half height of the source curve using Equation 1 (Yen et al., 2009).

$D=\frac{K \lambda}{\beta \cos \theta}$

Where $\mathrm{k}$ is a constant (indicative of crystallite perfection and is assumed to be 0.9 ); $\lambda(\AA)$ is the wave length of incident radiation (1.5406 $\AA$ ); $\beta$ (rad) is the width of the crystalline peak at half height and $\theta(\mathrm{deg})$ is the diffraction angle corresponding to the crystalline peak.

\subsection{Scanning Electronic Microscopy (SEM)}

The samples micrographs were produced via a scanning electron microscopy model; Phenom Eindhoven, Netherlands. It works with an electron intensity beam of $15 \mathrm{kV}$, while the samples to be observed were usually mounted on a conductive carbon imprint left by the adhesive tape. This is usually prepared by placing the samples on the circular holder and coated for 5 min to enable it conduct electricity.

\section{RESULTS AND DISCUSSION}

\subsection{Mechanical response of the composite}

It was observed that the 5wt.\% PLA-watermelon seed sample showed the highest overall maximum tensile stress (2.09 MPa). Ultimate tensile strength (UTS) for the albizzia and watermelon seeds reinforcement exhibited highest UTS of 1.70 and 2.09 MPa respectively at $5 \mathrm{wt} . \%$ and decreased with increment in weight percentage, showing improvement over neat PLA (Table 1). A similar trend was observed by Li et al. (2017) and Nasrin et al. (2017). They attributed this to good dispersion of chitin reinforcement in PLA and strong interfacial action between the polymer matrix and reinforcement. The overall mechanical performance of 
composites, depends on adhesion and compatibility between the polymer matrix and reinforcement, and crystallinity of the polymer matrix and reinforcement (Dufresne et al., 2003).

The ductility of the composites varies with different weight fractions of the reinforcement (Table 1). It was observed that the ductility of composites (PLA+albizia seed) at 10 and 15wt.\% show $50 \%$ improvement over the neat PLA. However, watermelon showed undulating patterns at various weight percentages, with $5 \mathrm{wt} . \%$ showing 165\% improvement over the neat PLA. From Table 1 it can be seen that the energy at break increases with an increase in the weight fraction of Albizzia reinforcement from 0.03 to $0.20 \mathrm{~J}$ while that of watermelon shows wavy pattern, which may be attributed to poor mixing. It is also noticed that PLA+albizia at $15 \mathrm{wt} . \%$ and PLA/Watermelon at 5wt.\% showed $100 \%$ and $400 \%$ improvement respectively over the neat PLA. This implies that the composite at these percentage reinforcements is tougher than the neat PLA with $0.01 \mathrm{~J}$ of energy.

Table 1. Strength characteristics of PLA and its composites.

\begin{tabular}{|c|c|c|c|c|c|c|c|c|c|c|c|c|}
\hline Sample & \multicolumn{3}{|c|}{$\begin{array}{l}\text { Ultimate tensile } \\
\text { strength (UTS) } \\
\quad(\mathrm{MPa})\end{array}$} & \multicolumn{3}{|c|}{$\begin{array}{c}\text { Energy at Break } \\
(\mathrm{J})\end{array}$} & \multicolumn{3}{|c|}{ Ductility \% } & \multicolumn{3}{|c|}{$\begin{array}{c}\text { Fracture stress } \\
\qquad \mathrm{MPa}\end{array}$} \\
\hline Filler wt.\% & 5 & 10 & 15 & 5 & 10 & 15 & 5 & 10 & 15 & 5 & 10 & 15 \\
\hline Neat PLA & & 1.52 & & & 0.10 & & & 0.06 & & & 1.11 & \\
\hline $\begin{array}{c}\text { PLA+Albizia } \\
\text { seed }\end{array}$ & 1.70 & 0.48 & 1.46 & 0.03 & 0.06 & 0.20 & 0.02 & 0.09 & 0.09 & 1.70 & 0.47 & 1.41 \\
\hline $\begin{array}{l}\text { PLA+Waterm } \\
\text { elon seed }\end{array}$ & 2.09 & 0.31 & 1.48 & 0.40 & 0.01 & 0.07 & 0.16 & 0.04 & 0.04 & 1.86 & 0.19 & 1.20 \\
\hline
\end{tabular}

Comparing the seeds particle fillers reinforced composites, the tensile strength at break of the PLA-seeds composites, at 5 wt.\%, and 15 wt.\% which are 1.70, 1.41 and 1.86, 1.20 for ALB seed particle reinforced and WM seed respectively was higher than that of neat PLA which is 1.11MPa (Table 1). This could be attributed to better interfacial bonding between the bio-seed particles and PLA (Dufresne et al., 2003).

\section{2. $X$-ray Diffraction Analysis}

The XRD spectra of neat PLA, PLA-watermelon and PLA-albizzia seeds are shown in Figs. 13. Neat PLA spectra showed a peak at $2 \Theta=16.7^{\circ}$ and $18.9^{\circ}$, which is typical of semi- crystalline 
material, with amorphous and crystalline peak. This result is similar to the findings of Reddy et al. (2008) and Jain et al. (2015), which reported the spectra to be found at $2 \Theta=16.7^{\circ}$ and $19^{\circ}$. The intensity of the peak around $2 \Theta=16.7^{\circ}$ decreased for all the composites compared to unreinforced PLA. These suggest a decrease in crystallinity in the composites; particularly the PLA/5wt. \%WM and PLA/5wt. \%ALB. The crystallite size of both PLA/5 wt.\% ALB and PLA/5wt.\%WM decreased compared to the unreinforced PLA. These values are shown in Table 2. Thus, the composites with higher crystallite (crystallinity is directly proportional to crystal size) sizes have lower UTS and those with lower crystallite sizes has higher UTS. This was also observed in the work of Sonia et al. (2019).

The crystallinity, $X_{\mathrm{c}}$ was calculated from the height ratio in the diffractogram using the Equation 2 (Juarez-de la Rosa et al., 2012).

$X c(\%)=\left\{\frac{l c}{l c+l a}\right\} * 100$

Where $I_{c}$ is the maximum intensity of crystalline region and $I_{a}$ is the intensity of amorphous region of the sample. This was done for crystalline peaks present for each component and the average values were calculated (Table 2).

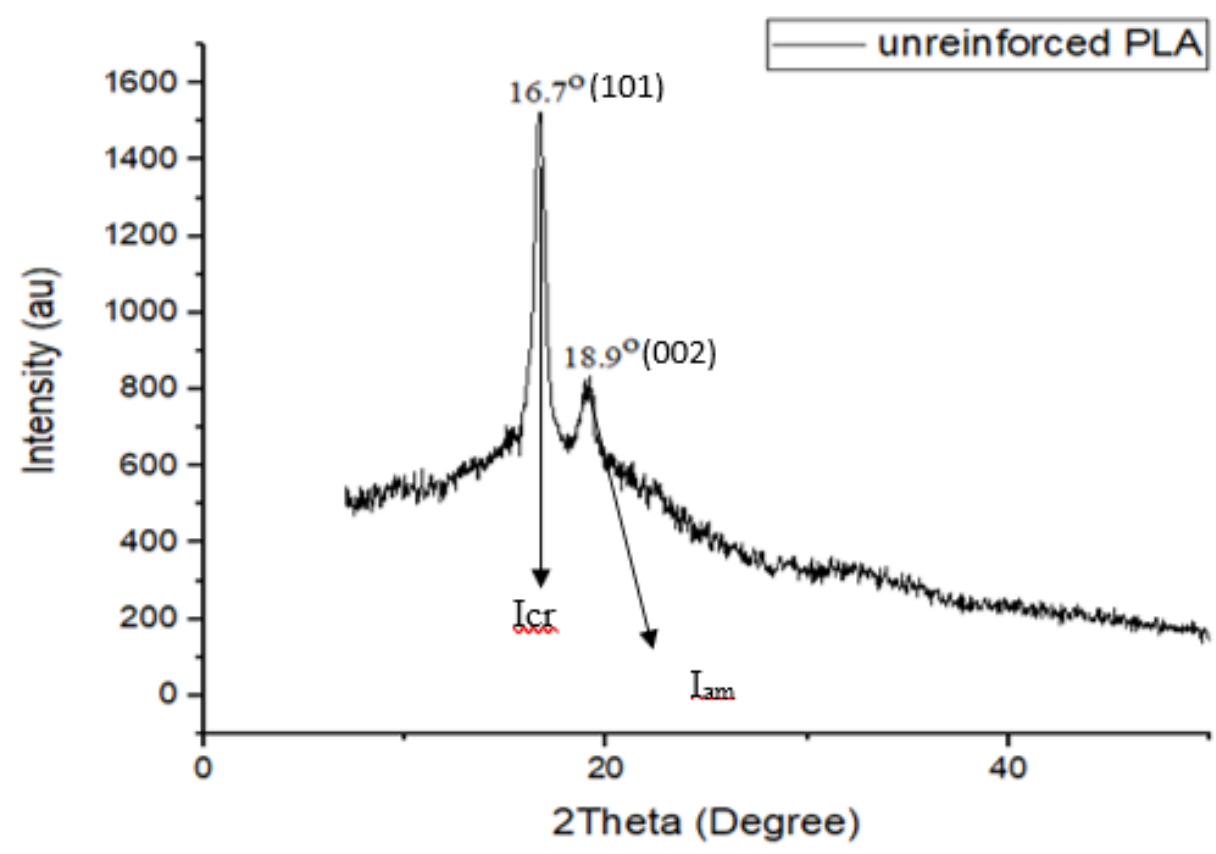

Fig. 1. XRD pattern of unreinforced PLA. 


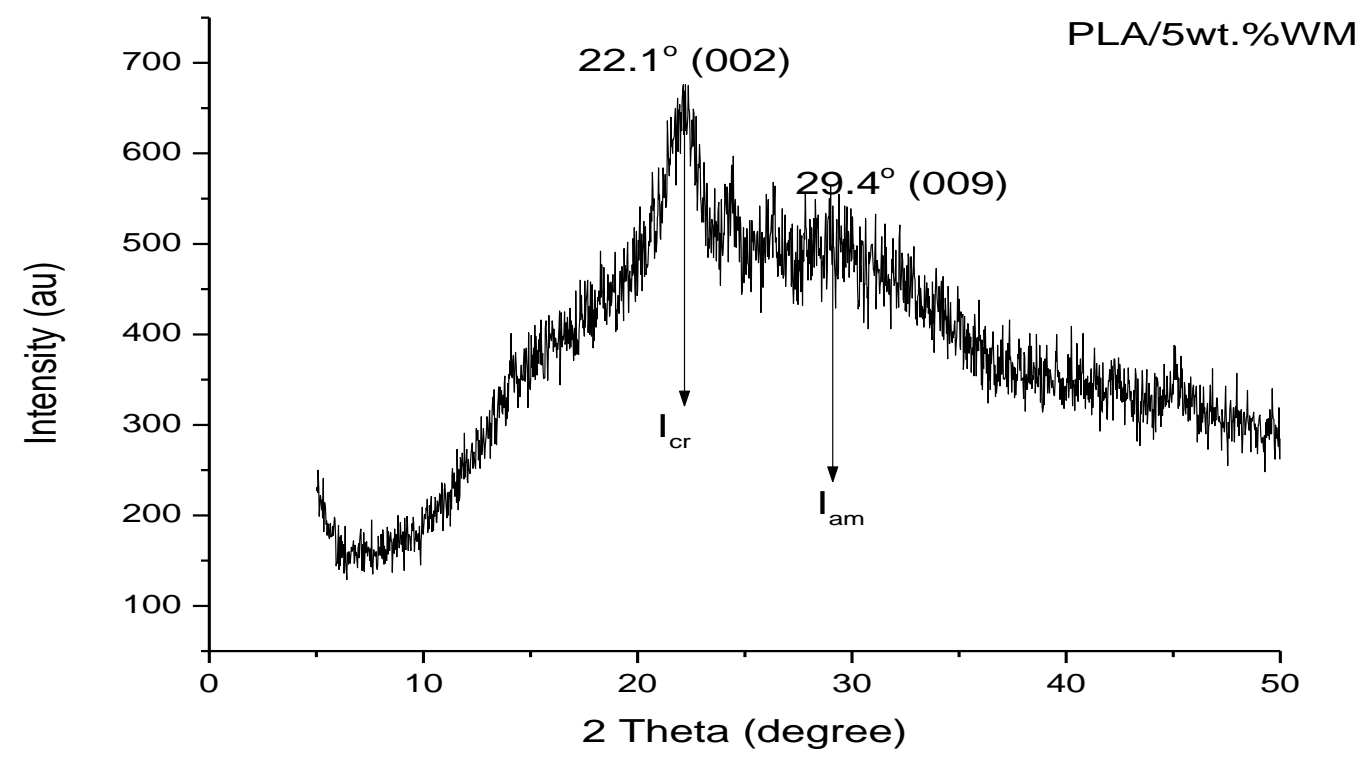

Fig. 2. XRD pattern of PLA/5 wt. \% watermelon seeds.

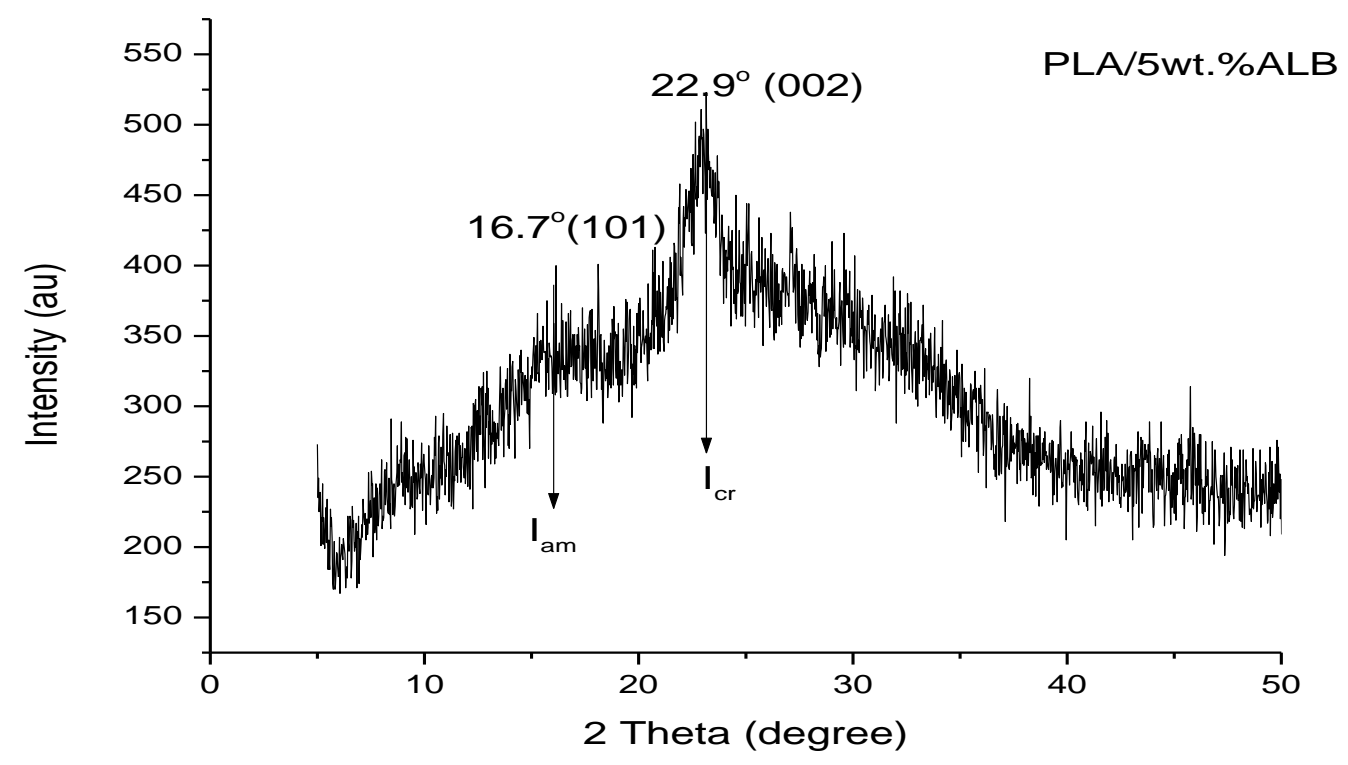

Fig. 3. XRD pattern of PLA/5wt.\% albizia seeds.

Table 2. Crystallite sizes of the composites.

\begin{tabular}{llll}
\hline Composites & Crl (\%) & Crystallite size $(\AA)$ & UTS (MPa) \\
\hline Neat PLA & 75.0 & 4.907 & 1.525 \\
PLA+5wt.\%WM & 65.4 & 0.229 & 2.092 \\
PLA+5wt.\% ALB & 65.7 & 1.837 & 1.704 \\
\hline
\end{tabular}




\subsection{Scanning Electron Microscopy}

The SEM microstructures of the composites are shown in Plates 1 to 2. Plate 1a shows clusters of the watermelon seeds at $10 \mathrm{wt} \%$ in the PLA matrix. This depicts an inhomogeneous composite, which could have resulted from poor mixing during composite production. The mechanical strength obtained for PLA-WM composites; at UTS dropped at $10 \mathrm{wt} \% \mathrm{WM}$ to $0.04 \mathrm{MPa}$ due to the presence of clusters. Plate $1 \mathrm{~b}$, at $5 \mathrm{wt}$. \% of water melon in PLA, matrix shows an evenly distributed PLA-WM blend with a continuous morphology and no noticeable void. This good dispersion network is responsible for better stress distribution between the PLA matrix and reinforcement, thus a better mechanical performance compared to the other samples.

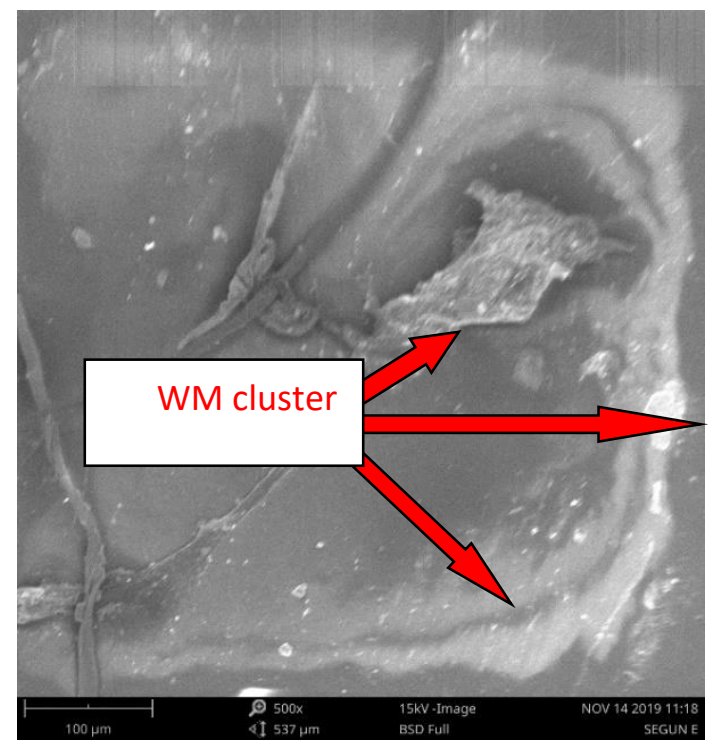

(a)

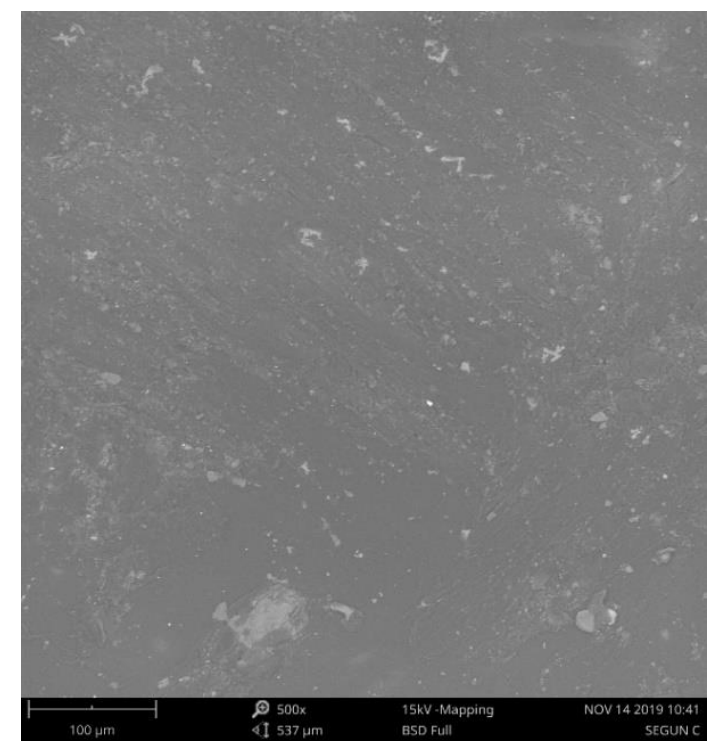

(b)

Plate 1. SEM micrographs at 100X Mag: (a) PLA/10wt.\%WM (b) PLA/5wt.\%WM.

In Plate 2a, PLA/10wt.\% ALB shows clusters in dendritic form, which imparted on its mechanical properties. The PLA/5wt.\% ALB in Plate $2 \mathrm{~b}$ showed an even distribution similar to the PLA/5wt. \%WM sample except that the surface shows some roughness with voids. This is probably the reason it has a lower UTS compared to the PLA/5wt. \%WM. Similar result was reported in the works of Laura et al. (2019). 


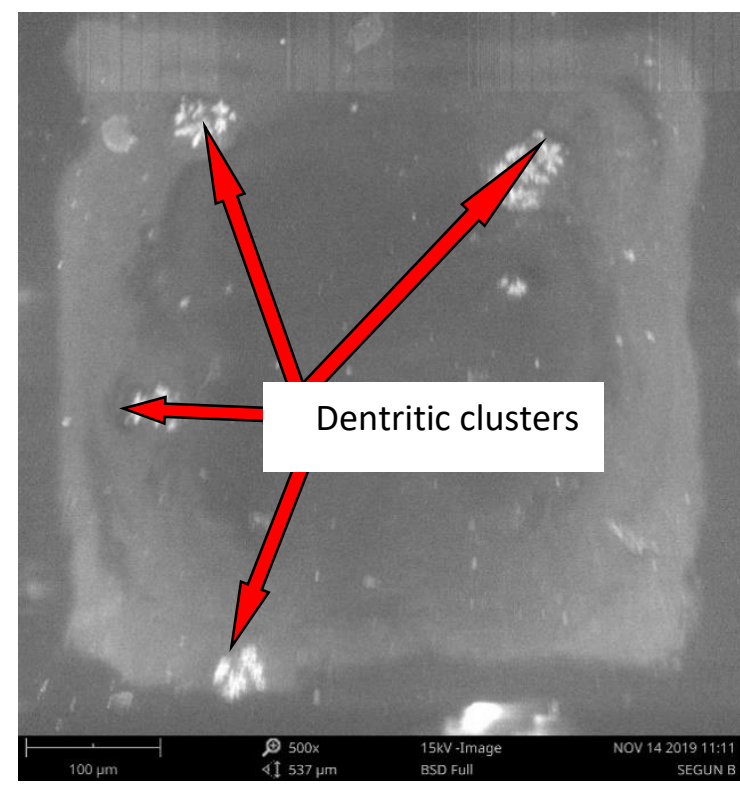

(a)

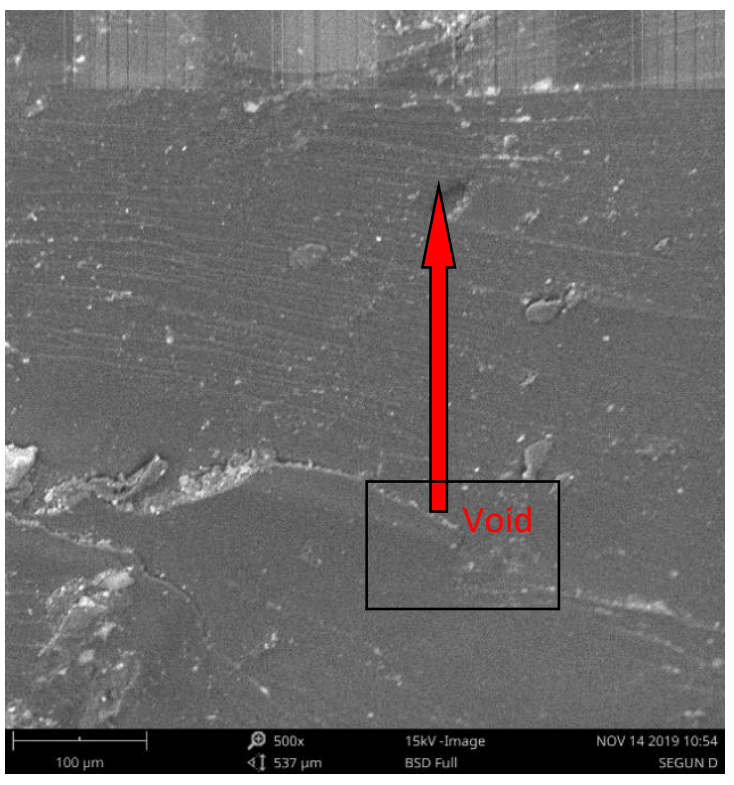

(b)

Plate 2. SEM micrographs at 100X Mag: (a) PLA/10wt.\%ALB (b) PLA/5wt.\%ALB.

\section{CONCLUSION}

The characterization of biowaste composites, with PLA the matrix and watermelon and albizzia seeds particles reinforcements have been carried out. The result of this study shows the possibility of using these bio-wastes as reinforcement for composite production. In the light of this the following conclusions are drawn.

- The tensile strength of Albizzia seed and watermelon at 5 wt.\% were $1.70 \mathrm{MPa}$ and 1.86MPa respectively. These shows an improvement over neat PLA with $1.52 \mathrm{MPa}$ and represent $12 \%$ and $22 \%$ improvement for Albizia seed and watermelon respectively. Therefore, it can be suggested that these composites have potential use as an implant for the skin, in the abdominal area where the strength ranges from 1-24MPa.

- From the SEM result, the distribution of the reinforcement within the matrix is the main cause of changes in the mechanical properties of the composite.

\section{REFERENCES}

Antonio, N., Nakagaito 1, Sohtaro, K. and Hitoshi, T. (2018) Polylactic Acid Reinforced with Mixed Cellulose and Chitin Nanofibers-Effect of Mixture Ratio on the Mechanical Properties of Composites J .Compos.Sci. 2, 36; doi: 10.3390/jcs2020036.(accessed Jan 17, 2020)

Chen, Y., Luke, M.G, John, A.K, John G.L., Higginbotham, C.L., and Devine, D.M. (2015). Halloysite nanotube polylactic acid composite. Polymer composite. 10.1002/pc.23794 
Dufresne, A., Dupeyre, D. and Paillet, M. (2013). Lignocellulosic flour-reinforced poly (hydroxybutyrate-co-valerate) Composites. Journal of Applied Polymer Science. 87 , 13021315.

Gbenebor, O.,Osabumwere, F. and Adeosun, O.(2020). Structural, Mechanical properties of low Polyethyline/Biomass Composite. Effects of particle size. Kufa journal of Engineering vol.11 (2), 67-83.

Jia, W., Gong, R. H. Soutis, C. and Hogg, P. J., (2013). Biodegradable Fibre Reinforced Composites Composed of Polylactic acid and Polybutylene Succinate Plastics, Rubber and Composites 43 (3), 83. DOI 10.1179/1743289813Y.0000000070.

Juarez-de la Rosa B.A., Quintana P., Ardission P.I., Yanez-Limon J.M., Alvarado-Gil J.J. (2012). Effects of thermal treatments on structure of two black coral species chitinous exoskeleton, J.Mater.Sci.47, 990-998.

Kamarudin, S. H., Abdullah, L. C., Aung, M. M., Ratnam, C. T., (2018) A study of Mechanical and Morphological Properties of PLA based Bio composites Prepared with EJO Vegetable oilbased Plasticiser and kenaf fibres IOP Conf. Series: Materials Science and Engineering 368 012011 doi:10.1088/1757-899X/368/1/012011.The Wood and Biofiber International Conference (WOBIC 2017).

Li, J., Li, J., Feng, D., Zhao, J., Sun, J. and Li, D. (2017). Comparative Study on Properties of Polylactic Acid Nanocomposites with Cellulose and Chitin Nanofibers Extracted from Different Raw Materials. Journal of Nanomaterials Vol. 2017. Article ID 7193263, 11 pages.

Mohammed,N. H. I (2006). Physical properties of western Sudan Watermelon (Citrullus Vulgaris) (Master Thesis University of Khartoum).

Nasrin, R., Biswas, S., Rashid, T.U., Afrin, S., Jahan, R.A., Haque, P. and Rahman, M.M. (2017). Preparation of Chitin-PLA laminated composite for implantable application. Bioactive Materials. 2, 199-207.

Ramengmawii, S., Mohammad, J., Hidayah, A., Sapuan, S. M., Mohammad, A., Naheed, S. (2018). Natural Fiber Reinforced Polylactic Acid Composites:A Review. Polymer Composites DOI $10.1002 / p c$

Sanjay, M.R., Arpitha, G.R., Naik, L.L., Gopalakrishna, K. and Yogesha, B. (2016) Applications of Natural Fibres and Its Composites: An Overview. Natural Resources, 7, 108114. http://dx.doi.org/10.4236/nr.2016.73011 
Shahid, S.A. and Firdou, N. (2012) "Antimicrobial screening of albizia lebbeck (1.) benth. And acacia leucophloea (roxb.). African Journal of Pharmacy and Pharmacology", 6(46) 3180-3183. Sonia, S., Ana, C., Abilio, S., Rogerio, S., (2019). Polyl(lactic acid)/Cellulose Films Produced From Composite Spheres prepared by Emulsion-Solvent Evaporation Method. 11, 66; doi:10.3390/polym11010066. www.mdpi.com/journal/polymers

Sun, Z., Zhang, L., Liang, D., Xiao, W., and Lin, J. (2017) Mechanical and Thermal Properties of PLA Bio composites Reinforced by Coir Fibres International Journal of Polymer Science Volume. Article ID 2178329, p.8 https://doi.org/10.1155/2017/2178329.

Yen, M. T, Yang, J. H, Mau, J. L. (2009). Physicochemical characterization of chitin and chitosan

from crab shells. Carbohydra. Polym.75:15-21. 